ISSN: 2288-2766 @ 2020 EABEA. http://eajbe.jams.or.kr doi: http://dx.doi.org/10.20498/eajbe.2020.8.3.37

\title{
Study on the Tasting of Distributors*
}

\author{
Sung-Heun LEE ${ }^{1}$, Hee-Joong HWANG ${ }^{2}$ \\ 1 First Author Ph.D. Student, Department of Business Administration, Yonsei University, Korea. \\ E-mail: sungheunlee@yonsei.ac.kr \\ 2 Corresponding Author Professor, Department of International Trade, Korea National Open University, Korea. \\ E-mail: ygodson@knou.ac.kr
}

Received: 18 August 2020. Revised: 16 September 2020. Accepted: 23 September 2020

\begin{abstract}
Purpose - Research on the mechanism by which tasting affects the purchase of related products and related products is still insufficient. Therefore, it is necessary to make good use of marketing practically how tasting affects taste and leads to consumption behavior.

Research design, data, and methodology - First, we provide tasting sampling for people with different impulsive purchasing tendencies and check whether this leads to purchasing behavior in the future. Second, it is necessary to measure 'face (or notion of courtesy)', which is a characteristic of Koreans, as a moderating variable for the effect of sampling. Third, it is proposed to look at how the effect of sampling appears differently over time.

Results - First, it is necessary to pay attention to the factors influencing the sampling effect in the product group that cannot produce a tasting situation such as general food or beverage. Second, research results may not apply to all actual marketing.

Conclusions - This study is judged to have contributed to resolving the question of whether the distribution store's tasting promotion is more effective and lasts longer than other promotions. It also suggested the possibility that the effect of tasting could be changed depending on whether the amount of tasting was limited or the subjects of tasting.
\end{abstract}

Keywords: Tasting, Sense of Taste, Sampling, Face, Promotion.

JEL Classification Code: C90, D83, L83, M15.

\footnotetext{
* This research was supported by Korea National Open University Research Fund

(c) Copyright: The Author(s)

This is an Open Access article distributed under the terms of the Creative Commons Attribution Non-Commercial License (http://Creativecommons.org/licenses/by-nc/4.0/) which permits unrestricted noncommercial use, distribution, and reproduction in any medium, provided the original work is properly cited.
} 


\section{Introduction}

Providing samples of products is a common promotion strategy for companies. The purpose of sampling is to encourage the trial use of the product in order to promote consumer purchase intentions (Heilman, Lakishyk, \& Radas, 2011; Rexha, Mizerski, \& Mizerski, 2010). Such sampling is particularly actively used in the food industry. For example, in the case of food such as wine, promotions such as sampling are more effective than general advertisements in order to increase the profitability of products (Vlachvei, Notta, \& Ananiadis, 2009). However, existing promotion-related studies have focused on research on price discounts and coupons. Research into promotional subcategories such as product trials, free samples, and free gifts is lacking (Peattie, 1998).

Although there are studies on the importance of sampling in experiential product sales, there are still insufficient studies on the psychological mechanism of sampling and measuring the specific effect of sensory sampling on purchases.

In particular, there are not many studies on the effects of tasting itself, but studies on the mechanism by which tasting affects the purchase of related products and related products are still insufficient. Therefore, it is necessary to make good use of marketing practically how tasting affects taste and leads to consumption behavior.

In addition, it is necessary to clarify various consumer behavioral variables and situational variables that affect the process of tasting promotions used in retail stores affecting consumers' purchases. Of course, in this process, there are various exogenous variables such as consumer personality, experience, and industry. Nevertheless, it is important to obtain implications that can become a standard for establishing business strategies for retailers using tasting.

\section{Literature Review}

The beginning of the food sampling research was Steinberg and Yalch (1978). Steinberg and Yalch (1978) inspected stout and nonobese customers in a market, how hungry the customers were, and the impact of deals of other staple things when customers were offered an in-store test (a donut in the bread shop segment). For the nonobese, if a customer was ravenous, the food test appeared to fulfill a portion of their appetite and they diminished their extra purchasing contrasted with the nonobese customers who were not eager. For the hefty customers, offering a food test expanded extra purchasing and this was just marginally directed by their degree of appetite. The creators guess that large customers are not as touchy to their inward signs of craving so offering an example may have expanded further the notability of food and they bought more.

Some studies have examined whether distracting shoppers when tasting food samples promotes purchases or not (Nowlis \& Shiv, 2005; Shiv \& Nowlis, 2004). Contrary to industry belief, it turns out that the more distracted shoppers are, the more follow-up choices for sample foods. The authors clarify these outcomes utilizing a twocomponent model in which a definitive joy a customer gets from tasting a food test is an element of an informational and an affective part. The affective component includes the emotional reactions of the customer and is related with relatively automatic processes. The informational component is a more target highlight of the tasting experience and identified with angles, for example, quality. This information component is involved more controlled procedures. Distracting a consumer impacts subsequent choice by expanding the effect of the affective component.

As such, food sampling is generally regarded as an effective marketing tool to promote the purchase of the product, but if you look at it intuitively, there is a possibility that the food sample provided will alleviate the hunger and thirst of potential buyers, thereby reducing the behavior to consume later. A study by Wadhwa, Shiv, \& Nowlis (2008) pointed out two conflicting views. As a result, sampling stimulates the consumer's state of motivation. This sampling proved to be effective in facilitating the purchase of the same beverage as the sample, the beverage different from the sample, and other products of other sections.

When we first taste a taste stimulant, our reaction may be positive. However, after eating for a while, the reactions that used to be positive may turn negative and become easily bored. Cabanac (1979) asked people to evaluate the pleasure of sugar solutions. When the sample of the solution was tasted and spit out, people's evaluation of the sugar solution was positive even after repeated multiple times. However, after tasting the sample and drinking it, what was pleasant at first becomes unpleasant afterwards, and in the end people refused to drink it any more. In other words, human appetite (purchasing decision) differed according to the degree of dissolution of their desires such as hunger (Cabanac, 1979). 
Based on the results of this experiment and many other similar results, Cabanac (1979) argued that a given irritant could be pleasant or unpleasant depending on the signal from the body. This proved that the cues of taste for predicting consumption behavior were not very effective.

Table 1: Study on the Tasting in Store

\begin{tabular}{|c|c|}
\hline Researcher & Study Results \\
\hline $\begin{array}{l}\text { Steinberg \& Yalch } \\
\text { (1978) }\end{array}$ & $\begin{array}{l}\text { At least for hefty customers, sampling can stimulate appetite and consequently boost } \\
\text { purchase quantities. }\end{array}$ \\
\hline Lammers (1991) & $\begin{array}{l}\text { For the time being (close to testing), giving a free sample positively affected deals of other } \\
\text { chocolate assortments, however not of the sampled assortment. }\end{array}$ \\
\hline $\begin{array}{l}\text { Fedoroff, Polivy, \& } \\
\text { Herman (1997) }\end{array}$ & $\begin{array}{l}\text { Pre-exposure to the smell of heating pizza did not impact hunger evaluations and food } \\
\text { utilization contrasted with no presentation in subjects that had refrained from eating } 2 \mathrm{~h} \\
\text { preceding the investigation. }\end{array}$ \\
\hline $\begin{array}{l}\text { Shiv \& Nowlis } \\
\text { (2004) }\end{array}$ & \multirow{2}{*}{$\begin{array}{l}\text { They look at the impact of diverting (musical) input on food decision. Diverting buyers } \\
\text { (imposing cognitive burden) while taste testing brings about more noteworthy spotlight on } \\
\text { the affective versus informational component; this improves the probability of picking a } \\
\text { more affective product (e.g., milk chocolate vs. soy chocolate) and furthermore } \\
\text { consumption pleasure. }\end{array}$} \\
\hline $\begin{array}{l}\text { Nowlis \& Shiv } \\
(2005)\end{array}$ & \\
\hline $\begin{array}{l}\text { Wadhwa, Shiv, \& } \\
\text { Nowlis (2008) }\end{array}$ & $\begin{array}{l}\text { Items high in reward value can expand attractive quality and consumption of other high } \\
\text { prize things. }\end{array}$ \\
\hline $\begin{array}{l}\text { Heilman, Lakishyk, } \\
\text { \& Radas (2011) }\end{array}$ & $\begin{array}{l}\text { Conveying free samples prompted preliminary for item. It could help in item changing } \\
\text { from planned to promoted item category. }\end{array}$ \\
\hline $\begin{array}{l}\text { Tal \& Wansink } \\
(2015)\end{array}$ & Food sampling can prime healthier or less healthy decisions. \\
\hline
\end{tabular}

\section{Research direction on tasting}

\subsection{Tasting marketing}

Marketing managers need to consider consumers' experiential and sensory aspects when implementing strategies. In particular, marketing of experiential products, such as food, beverages, cosmetics, etc., should examine the relationship between sensory organs (such as taste, smell, and color) and consumers' purchases (Krishna, 2012; Troye \& Supphellen 2012). In addition, in product lines where sensitivity is important (e.g., spices, food/beverage, music), it is important for marketers to provide opportunities for consumers to sample before purchasing the product (Biswas, Grewal, \& Roggeveen). , 2010; Nowlis \& Shiv, 2005; Shiv \& Nowlis, 2004; Wadhwa, Shiv, \& Nowlis, 2008). In practice, retailers are increasingly offering free samples of the food and beverage items they sell. Businesses use sampling because sampling is more effective and less expensive than traditional advertising.

Test use of a product affects the formation of beliefs and attitudes toward the product. However, research on how tasting or tasting experience related to directly taste affects consumers' emotional state and cognitive purchasing behavior is insufficient.

Tasting marketing means providing an opportunity to taste in food sales. Eating bread at a bakery while going on the streets, sausages and various side dishes, and beverages prepared and handed out at school booths are also subject to tasting marketing. Tasting and tasting experiences can attract young consumers with no purchasing experience. In addition, free trial events and tasting events can go beyond the limits of general advertising. Moreover, through such a plan, the consumption class can be expanded. The reason tasting marketing is useful is that tasting relieves consumers' feelings of perceived risk and doubt about the product.

Examples of tasting marketing include vitamins that can be chewed like gum, drinks containing ginseng that can be drunk like regular beverages, and diet products that can be eaten with water like raw food. If you provide intake 
tips and product information at the retail store's tasting corner, it is highly likely to lead to the purchase of related products. In general, it is common sense that the sales volume when tasting is higher than when it is not, but the gap varies depending on the type of product or service provided. In the case of food, taste and quality cannot be verified unless you try it in advance. Therefore, it will be important to promote the product through tasting. The reason why the effect of tasting or tasting marketing is so positive is that consumers can diagnose the quality of a product through trial. Tasting samples ensure consumer diagnostics of product attributes (Gerlich, Browning, \& Westermann, 2011).

Practically, experiential marketing raises the brand's product awareness, and by directly delivering taste satisfaction through tasting, it can help rational shopping and increase the reliability of the product. In other words, tasting marketing provides information on product design, taste, and function at the same time, which is very useful to consumers.

\subsection{Suggestions for research direction}

First, we provide tasting sampling for people with different impulsive purchasing tendencies to see if this leads to future purchasing behavior. The taste-stimulating effect of tasting sampling will depend on: whether the consumer has previously been exposed to the related product (purchasing experience) and the exposure situation (planned purchase or impulsive purchase) (Gerlich, Browning, \& Westermann, 2011; Kirk-Smith, 1994).

Sampling marketing is a kind of emotional marketing. Therefore, it is expected that people with a lot of cognitive exploration, high risk susceptibility, and high impulsive purchasing tendencies will further pursue reward-seeking behavior in the future.

Second, it is necessary to measure 'face (or notion of courtesy)', which is a characteristic of Koreans, as a moderating variable for the effect of sampling. At least occasionally, Koreans may be tasting at a distribution store and then embarrassed by the excessive kindness of the staff, feeling a kind of sorry, and buying things because of their face. In terms of face, it means 'a face that is proud to treat others'. Brown and Levinson (1987) argued that the desire to maintain face is a phenomenon that occurs in all cultures, and that people want to protect their face and have a desire to prevent their face from being damaged. Of course, the degree of face varies depending on status, age, and gender. In other words, the degree of face may be different depending on how consumers are aware of their identity, status, or personality. In a situation where consumers ask various questions and sellers spend time and labor explaining products, consumers may experience a state of psychological anxiety about how others evaluate their morality if they do not purchase.

Therefore, when measuring the effect of sampling, meaningful results can be obtained if Koreans use emotions such as face consciousness and sorry for tasting samples at distribution stores as moderating variables.

Third, it is necessary to examine that the effect of sampling appears differently over time. Time is an important factor in measuring the sampling effect. At this time, the influence of time may vary depending on the level of consumer experience. Consumers who purchase immediately after tasting and consumers who only experience tasting will have differences in purchasing behavior when exposed to the purchase situation after a certain period. Also, the amount of tasting may vary over time. For example, a consumer who has been offered unrestricted tasting can reduce the number of purchases on the spot because thirst or hunger is partially quenched, but good memories remain for a long time, leading to more purchases in the future. On the other hand, consumers who have experienced limited tasting may not proceed to consumption because their memory of the product rapidly decreases as time passes. In other words, consumers will be able to better remember the products they sampled if they form positive values based on satisfying experiences.

The above suggestions can be summarized through hypotheses as follows.

Hypothesis 1: Tasting will have a positive effect on the purchase intention of related products.

Hypothesis 2: The effect of tasting on product purchase intention will be moderated by the consumer's impulsive purchasing tendency.

Hypothesis 3: The effect of tasting on product purchase intention will be moderated by the consumer's face orientation.

Hypothesis 4: The effect of tasting on product purchase intention will decrease with time.

Hypothesis 4-1: Consumers who purchase immediately after tasting will have higher purchase intentions in the future than consumers who only experienced tasting. 
Hypothesis 4-2: Consumers who are provided with unlimited tasting will have higher product purchase intentions than consumers who have experienced limited tasting.

\section{Conclusions}

It is true that information such as product characteristics, such as price discount, quality guarantee conditions, and brand reputation, has a great influence in the consumer's purchasing decision. However, it should not be overlooked that the efforts of marketers in purchasing situations can have a great influence on consumers' choices and preferences.

If tasting does not lead to purchase on the spot, human senses and memories are often uncertain, so it is natural for consumers with tasting experience to question whether they will purchase again in the future. In addition, it is difficult to measure and interpret the effect of tasting because human senses are inherently vague and difficult to measure (Shapiro \& Spence, 2002).

Sampling, such as tasting, has a complex effect on consumers' taste and behavior. In other words, it is difficult to control numerous variables in order to verify the effectiveness of tasting sampling. Therefore, there is a need to derive common themes and implications that transcend humans' different personalities, experiences, and physical and mental conditions.

On the other hand, when consumers want to sample or taste a sample of the product, it is thought that there will be many cases where they have already made a choice and use the sample rather than experiencing it simply because it is free. In this case, it cannot be said that it is the effect of the sample, so it is necessary to control the consumer who has such a purchase intention in the current data.

Additional related future studies are as follows.

First, it is necessary to pay attention to the factors that affect the sampling effect in the product group that cannot produce the tasting situation such as general food or beverage. That is, it can be considered that the suitability of the original product and the sample product can have an effect as an important moderating variable. For example, consider two cases. You can think of a case where a beverage maker offers a sample of a bundle cup, and the case where the company provides a sample of cosmetics that has nothing to do with a drink. Providing samples of existing products and suitable products will have a positive effect on sales growth through positive association transfer and product alliance strategies.

Second, it should be considered that research results may not apply to all actual marketing. Therefore, we need to analyze market conditions and customers well so that the company can produce the best results desired. Sampling that lacks detailed planning and does not predict consumer reactions or expectations fails. Tasty food is an experience material that allows you to know its quality after tasting, while healthy food that is good for the body is a trustworthy material that makes it difficult to experience the effect even after tasting. Therefore, compared to general foods, health foods may not have satisfactory success even if tasting events are conducted at enormous cost. Therefore, in this case, it would be more effective to use other promotional tools rather than sampling. Marketers of health food companies can apply methods such as finding more suitable media for advertising or hiring competent salespeople.

Companies and retailers have the purpose of using tasting in stores to increase sales, but the effect of this is still not convinced. This study contributed to resolving the question of whether the distribution store's tasting promotion is more effective and lasts longer than other promotions. In this process, we proposed the possibility that the effect of tasting could vary depending on whether the amount of tasting was limited. In addition, since the effect of tasting may vary depending on the target audience, it is necessary for retailers to select a suitable consumer segment for tasting promotion. 


\section{References}

Biswas, D., Grewal, D., \& Roggeveen, A. (2010). How the order of sampled experiential products affects choice. Journal of Marketing Research, 47(3), 508-519.

Brown, P., \& Levison, S. (1987). Politeness: Some Universals in Languages, Cambridge University Press, p. 52.

Cabanac, M. (1979). Sensory pleasure. The Quarterly Review of Biology, 54(1), 1-29.

Fedoroff, I. D., Polivy, J., \& Herman, C. P. (1997). The effect of pre-exposure to food cues on the eating behavior of restrained and unrestrained eaters. Appetite, 28(1), 33-47.

Gerlich, R. N., Browning, L., \& Westermann, L. (2011). Consumer Utilization of an Advertising Stimulus: The Effect of Peel'n Taste Marketing System on Customer Attitudes, Product Feelings and Likelihood of Purchase. Academy of Marketing Studies Journal, 15(2), 103.

Heilman, C., Lakishyk, K., \& Radas, S. (2011). An empirical investigation of in-store sampling promotions. British Food Journal, 113(10), 1252-1266.

Kirk-Smith, M.D. (1994). Cultural and Olfactory Communication. in Ethological Roots of Culture, R. Allen Gardner et al., eds., Boston: Kluwer, 385-406.

Krishna, A. (2012). An Integrative Review of Sensory Marketing: Engaging the Senses to Affect Perception, Judgment, and Behavior. Journal of Consumer Psychology, 22(3), 332-351.

Lammers, H. B. (1991). The effect of free samples on immediate consumer purchase. Journal of Consumer Marketing, 8(2), 31-37.

Nowlis, S., \& Shiv, B. (2005). The Influence of Consumer Distractions on the Effectiveness of Food-Sampling Programs. Journal of Marketing Research, 42(2), 157-168.

Peattie, S. (1998). Promotional competitions as a marketing tool in food retailing. British Food Journal, 100(6), 286294.

Rexha, D., Mizerski, K., \& Mizerski, D. (2010). The effect of availability, point of purchase advertising, and sampling on children's first independent food purchases. Journal of Promotion Management, 16(3), $148-166$.

Shapiro, S., \& Spence, M. T. (2002). Factors affecting encoding, retrieval, and alignment of sensory attributes in a memory-based brand choice task. Journal of Consumer Research 28(4), 603-617.

Shiv, B., \& Nowlis, S. M. (2004). The effect of distractions while tasting a food sample: The interplay of informational and affective components in subsequent choice. Journal of Consumer Research, 31(3), 599-608.

Steinberg, S. A., \& Yalch, R. F. (1978). When eating begets buying: The effects of food samples on obese and nonobese shoppers. Journal of Consumer Research, 4(4), 243-246.

Tal, A., \& Wansink, B. (2015). An apple a day brings more apples your way: Healthy samples prime healthier choices. Psychology \& Marketing, 32(5), 575-584.

Troye, S. V., \& Supphellen, M. (2012). Consumer Participation in Coproduction: "I Made It Myself" Effects on Consumers' Sensory Perceptions and Evaluations of Outcome and Input Product. Journal of Marketing, 76(2), 33-46.

Vlachvei, A., Notta, O., \& Ananiadis, I. (2009). Does advertising matter? An application to the Greek wine industry. British Food Journal, 111(7), 686-698.

Wadhwa, M., Shiv, B., \& Nowlis, S. M. (2008). A bite to whet the reward appetite: The influence of sampling on reward-seeking behaviors. Journal of Marketing Research, 45(4), 403-413. 